\title{
On the measurement of the surface energy budget over a land surface during the summer monsoon
}

\author{
G S BHAT* and S C ARUNCHANDRA \\ Center for Atmospheric and Oceanic Sciences, Indian Institute of Science, Bangalore 560 012, India. \\ *e-mail:bhat@caos.iisc.ernet.in
}

The measurement of surface energy balance over a land surface in an open area in Bangalore is reported. Measurements of all variables needed to calculate the surface energy balance on time scales longer than a week are made. Components of radiative fluxes are measured while sensible and latent heat fluxes are based on the bulk method using measurements made at two levels on a micrometeorological tower of $10 \mathrm{~m}$ height. The bulk flux formulation is verified by comparing its fluxes with direct fluxes using sonic anemometer data sampled at $10 \mathrm{~Hz}$. Soil temperature is measured at 4 depths. Data have been continuously collected for over 6 months covering pre-monsoon and monsoon periods during the year 2006. The study first addresses the issue of getting the fluxes accurately. It is shown that water vapour measurements are the most crucial. A bias of $0.25 \%$ in relative humidity, which is well above the normal accuracy assumed by the manufacturers but achievable in the field using a combination of laboratory calibration and field intercomparisons, results in about $20 \mathrm{~W} \mathrm{~m}^{-2}$ change in the latent heat flux on the seasonal time scale. When seen on the seasonal time scale, the net longwave radiation is the largest energy loss term at the experimental site. The seasonal variation in the energy sink term is small compared to that in the energy source term.

\section{Introduction}

Land surface temperature is an important meteorological variable and is required in many practical applications. It is desirable that we understand its evolution on different time scales ranging from few hours (e.g., to predict the occurrence of thunderstorms) to 100s of years (e.g., climate change related issues). The evolution of surface temperature is governed by the surface energy balance. Absorbed solar radiation is the primary source of energy, and long term (i.e., climatic) equilibrium means that this energy is eventually removed from the surface and transferred to the atmosphere. The energy loss can be in the form of sensible $(S H F)$ and latent $(L H F)$ heat fluxes, net long wave radiation $(N L W)$ and advection $\left(Q_{A}\right)$. On shorter time scales, heat flux into the ground $(G)$ and energy storage in the canopies $(S)$ also become important (figure 1).

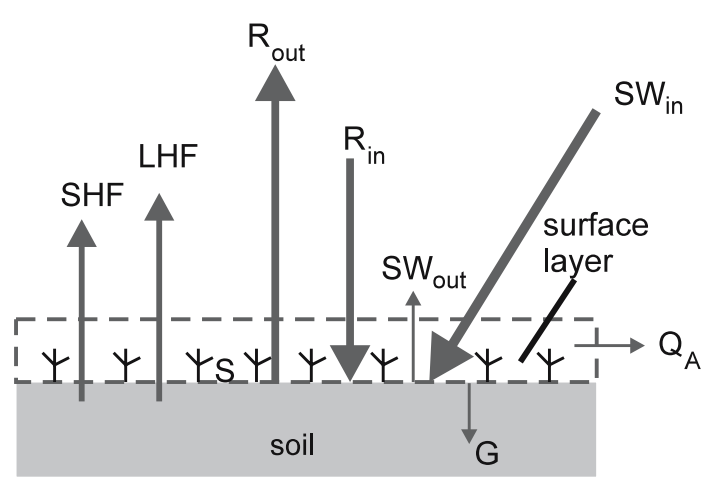

Figure 1. A schematic of the components of energy flux at a land surface. Arrows point the direction of energy transfer and their size is indicative of the relative magnitudes of the components. Surface is assumed to have some vegetation.

In order to understand the surface energy balance on different time scales, we need to know not only

Keywords. Surface fluxes; energy budget; land experiment; summer monsoon; atmospheric sciences; climate; experiments. 
the net surface heat flux $\left(Q_{\text {net }}\right.$, defined in section 3$)$ but also its individual components. This understanding enters numerical models (e.g., global circulation models and regional models) being run to predict weather and climate.

Among the different components of surface energy balance, radiative fluxes and ground heat fluxes can be measured by the instruments. $S H F$ and $L H F$ are major loss terms, however, not directly measurable by instruments. So is $Q_{A}$ but often neglected under the assumption of horizontal homogeneity. In numerical models and for the data coming from routine meteorological observations, $S H F$ and $L H F$ are estimated from knowing temperature, wind speed and water vapour concentration (or relative humidity, $R H$ ) and employing empirical relations (so called bulk methods). The Monin-Obukhov (M-O) similarity theory (Monin 1970; Businger et al 1971; Monin and Yaglom 1975), which is valid for a convective boundary layer, is the most widely used theory in the estimation of SHF and $L H F$ (e.g., Kaimal and Finningan 1994). A large number of individual and collective observations have been carried out in the past to understand the atmospheric boundary layer and develop flux relations in forced (e.g., Businger et al 1971; Dyer 1974) and natural convection limits (e.g., Rao and Narasimha 2006). These formulations are validated and fine-tuned by comparing their estimated fluxes with those computed from the eddy correlation method (ECM, Businger et al 1971; Beljaars and Holtslag 1991). ECM uses the definition of a flux in a stationary turbulent flow due to turbulent fluctuations to estimate $S H F$ and $L H F$ and hence the fluxes so obtained are also known as direct fluxes. Several assumptions are made in ECM including that the flow is turbulent and stationary (Monin and Yaglom 1975). Experience shows that the conditions in the atmosphere remain stationary less than $20 \%$ of the time and that too for durations less than an hour at a time. There are also times when wind speed is low and the boundary layer very stable; the flow may be time dependent but not turbulent in the classical sense. The direct fluxes are normally calculated for the stationary data stretches and used in developing the bulk flux relations. Extensions to non-stationary as well as non-turbulent flow conditions are being attempted (e.g., Mahrt 2007, 2008; Zilitinkevich and Esau 2007), however, these flux algorithms have not been tested sufficiently to apply them routinely.

The main difficulty lies in the fact that there are no direct methods to calculate $S H F$ and $L H F$ for non-stationary conditions. We know from experience that the heat capacity of the land surface is not large, and therefore on monthly and seasonal time scales, almost all the absorbed solar energy is returned to the atmosphere. Therefore, one indirect way of verifying the overall accuracy of the surface flux formulations is to look at the long term behaviour of $Q_{\text {net }}$. While a large number of boundary layer experiments have been carried out in the last 50 years, to our knowledge, none of them have addressed the surface energy balance on monthly and seasonal time scales. In the last 10 years, a global network of micrometeorological tower sites are being established under the international FLUXNET programme, where continuous measurements of the exchanges of carbon dioxide $\left(\mathrm{CO}_{2}\right)$, water vapor, and energy between terrestrial ecosystem and atmosphere are being carried out (Wilson et al 2002). At these sites, radiative fluxes are accurately measured and fluxes of $\mathrm{CO}_{2}$, water vapor and sensible heat are calculated from ECM using sonic anemometer and infrared sensor data (e.g., Anthoni et al 1999; Hollinger et al 1999; Schmid et al 2000; Wilson and Baldocchi 2000). These FLUXNET sites have been set up in North America, Europe, Australia and Asia (Japan, China, Korea and Thailand) enabling the precise calculations of surface energy balance on different time scales purely based on observed/measured fluxes. Results show that there is a general lack of closure at most sites, with the available energy (net radiation minus the energy stored) larger than the sum of $S H F$ and $L H F$ (e.g., Wilson et al 2002). The mean imbalance is about $20 \%$. (The advection term is neglected in these calculations on the ground that the sites chosen are horizontally homogeneous.)

While such comprehensive measurements are yet to be taken up in India, there have been experiments here where surface fluxes were measured [e.g., the Monsoon Trough Boundary Layer Experiment (MONTBLEX) in 1990 (Narasimha et al 1997), Land Surface Processes Experiment (LASPEX) during 1997-98 (Vernekar et al 2003)]. One common feature among the previous Indian experiments is that the data time series is discontinuous and continuous measurements covering an entire season are missing. Further, these measurements are not comprehensive in the sense that in some cases radiation data are not available while in other experiments the humidity data. Therefore, continuous time series of sufficient duration and including all variables needed to study the seasonal energy balance based on measured data alone is missing in the Indian context.

The present study, aimed at partially filling this gap, has two main objectives. The first objective is to understand what it takes to experimentally measure the components of the surface fluxes reliably. The second objective is to build a time series that enables the calculation of the seasonal surface energy balance based on the measured fluxes 
only. A micrometeorological tower was set up and instrumented at two levels above the ground for this purpose. The experimental arrangement is described in section 2 , section 3 briefly explains the theory required to calculate the fluxes, section 4 presents results, discussion is in section 5 and conclusions are in section 6 . It is shown that the calculated surface energy balance is very sensitive to even small errors in the relative humidity difference between two levels. The overall required accuracy of temperature and relative humidity measurements is much more than the normal accuracy levels promised by even the best makes of these sensors. A combination of laboratory calibration and intercomparison helps in reducing the inherent differences between the sensors substantially to below the manufacturer specifications. Another finding is that at this location, the net longwave radiation and not $S H F$ or $L H F$, is the largest energy loss term during the summer monsoon period.

\section{Experimental setup}

A $10 \mathrm{~m}$ high micrometeorological tower was installed in an open area in the airfield located within the campus of the Indian Institute of Science (IISc), Bangalore, India $\left(13.01^{\circ} \mathrm{N}\right.$, $77.34^{\circ} \mathrm{E}$ ). Figure 2 shows a photograph of the tower taken at an angle approximately normal to the then prevailing wind direction. The ground is flat and the tower site is covered with grass and small bushes, and the surrounding area is clear of any tall trees within a radius of at least $50 \mathrm{~m}$. In the upstream direction of wind, natural vegetation (grass) is present over a distance of more than $200 \mathrm{~m}$ which is reasonably homogeneous and grass was not cut to maintain the natural conditions even in the immediate neighborhood of the tower. Along the upwind direction, the homogeneity is better than that seen in the photograph and we believe that roughness, albedo and surface emissivity at the tower location are reasonably representative of the upwind area. The fetch (an upwind distance with uniform surface characteristics) along the west and south-west directions (the direction of the prevailing winds during the summer monsoon season) was few hundred meters and along the north and north-east direction (direction of winds during winter) was about $75 \mathrm{~m}$. Table 1 shows the sensor makes and the manufacturer specified accuracies. Temperature $(T)$, relative humidity, horizontal component of wind speed $(U)$ and wind direction instruments were mounted at two levels, namely 2 and $8 \mathrm{~m}$ (figure 2). All components of the radiation were measured using radiation instruments (pyranometers and

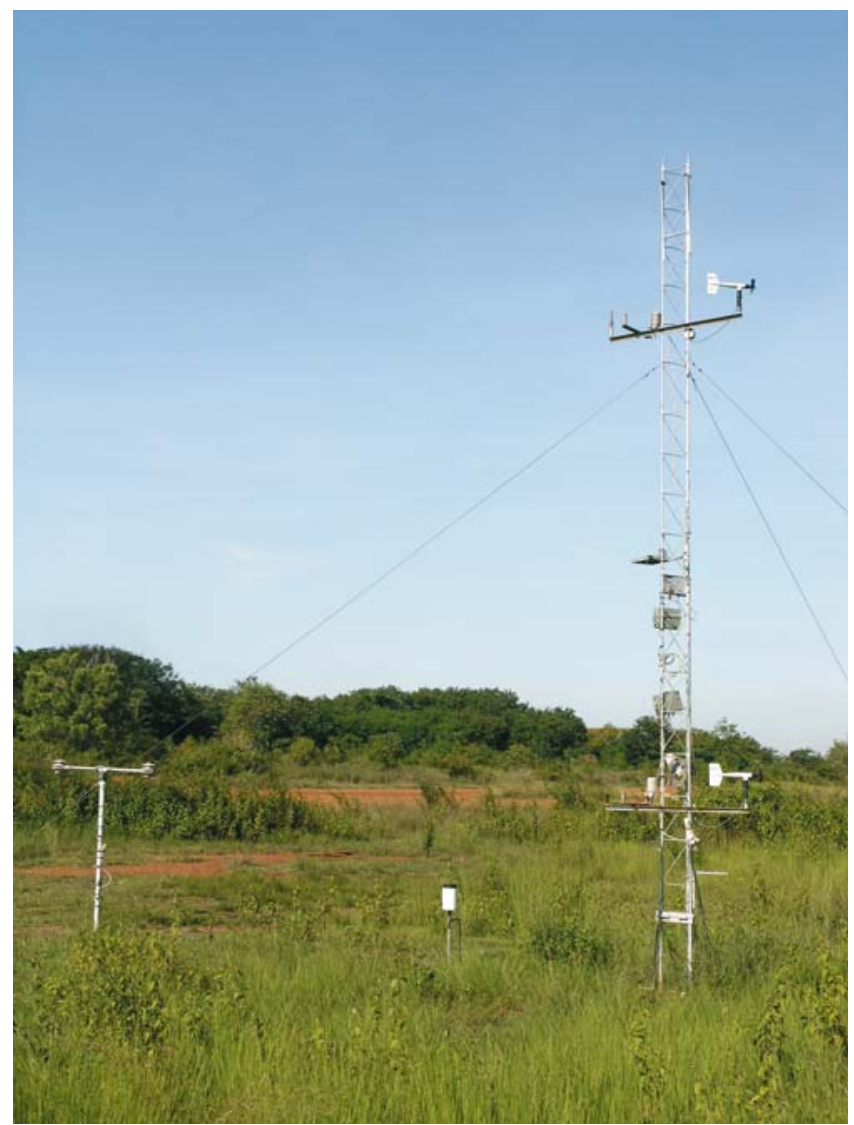

Figure 2. Photograph showing the experimental setup in the field. Vegetation at the site was allowed to grow naturally.

pyrgeometers) installed on a separate $2 \mathrm{~m}$ mast (figure 2). The radiation instruments installed are of Eppley make, regarded to be one of the most reliable, commercially available radiation instruments. Our choice for this make was influenced by its selection in Woods Hole's IMET (Improved Meteorology) system (Hosom et al 1995). Soil temperature was measured at 4 depths, namely $0.05,0.1,0.15$ and $0.2 \mathrm{~m}$. All sensors and data loggers were powered by a $12 \mathrm{~V}$ battery which was charged by a solar cell. The data were sampled every 5 seconds, averaged for 2 minutes and stored. Results shown correspond to the period May-October 2006.

Further, a sonic anemometer was installed at $2 \mathrm{~m}$ height on the tower and its data were collected during 30 May to 12 July 2006. This sonic anemometer measured three components of wind velocity and air temperature. Data were acquired at $10 \mathrm{~Hz}$ rate and stored in a PC. Running the sonic anemometer and $\mathrm{PC}$ required much more power than the solar panel could provide. Since the line power was not available at the tower site, these instruments were operated using a car battery, which lasted for about 20 hours when fully charged. Therefore, the sonic anemometer time series is not continuous and there 
Table 1. Sensors used in the present experimental setup and their specifications. These instruments were procured during BOBMEX (Bhat et al 2001) and ARMEX (Bhat et al 2005, Rao 2005), and redeployed after repair or maintenance so that the data accuracies are not compromised.

\begin{tabular}{|c|c|c|c|}
\hline Parameter/Instrument & Sensor & Accuracy & Make and model \\
\hline Air temperature & $\begin{array}{l}\text { Platinum resistance } \\
\text { thermometer }\end{array}$ & $\pm 0.2^{\circ} \mathrm{C}$ & $\begin{array}{l}\text { ROTRONICS, MP100H } \\
\text { with Hygroclip S3 }\end{array}$ \\
\hline Relative humidity & Capacitance & $\pm 1.5 \%$ & $\begin{array}{l}\text { ROTRONIC, MP100H with } \\
\text { Hygroclip S3 }\end{array}$ \\
\hline Pressure & Capacitance & $\pm 0.3 \mathrm{hpa}$ & VAISALA, PTB100A \\
\hline $\begin{array}{l}\text { Wind speed and wind } \\
\text { direction }\end{array}$ & $\begin{array}{l}\text { Propeller, } \\
\text { potentiometer }\end{array}$ & $\begin{array}{l} \pm 0.3 \mathrm{~m} \mathrm{~s}^{-1} \text { or } 1 \% \text { of } \\
\text { reading, } \pm 3^{\circ} \mathrm{C}\end{array}$ & $\begin{array}{l}\text { R.M. YOUNG, Wind } \\
\text { Monitor } 05103\end{array}$ \\
\hline Rain gauge & Tipping bucket & $0.1 \mathrm{~mm}$ per 50 tips & R.M. YOUNG, 52203 \\
\hline Soil temperature & $\begin{array}{l}\text { Platinum resistance } \\
\text { thermometer }\end{array}$ & $\pm 0.3^{\circ} \mathrm{C}$ & $\begin{array}{l}\text { HONEY WELL, HEL-700, } \\
\text { thin film }\end{array}$ \\
\hline $\begin{array}{l}\text { Multi-plate radiation } \\
\text { shield }\end{array}$ & & - & R.M. YOUNG \\
\hline Shortwave radiation & Thermopile & $\begin{array}{l}* \text { absolute accuracy } \\
\pm 3-4 \% \text { and relative } \\
\text { accuracy } \pm 2 \%\end{array}$ & EPPLEY, PSP \\
\hline Longwave radiation & $\begin{array}{l}\text { Thermopile with } \\
\text { temperature } \\
\text { compensation }\end{array}$ & ${ }^{*} \pm 10 \mathrm{~W} \mathrm{~m}{ }^{-2}$ & EPPLEY, PIR \\
\hline Wind vector $(u, v, w)$ & Sonic anemometer & $0.1 \mathrm{~m} \mathrm{~s}^{-1}$ & METEK, USA-1 \\
\hline Temperature & Sonic anemometer & $0.01^{\circ} \mathrm{C}$ & METEK, USA-1 \\
\hline Data logger & & & Campbell, CR10X \\
\hline
\end{tabular}

*Eppley does not specify the actual accuracy of their radiation instrument. The numbers are based on the reports from researchers who carried out calibration and intercomparison experiments.

are data gaps. The sonic data are basically used to verify the bulk fluxes, and this purpose was served with the data collected.

The calibration of instruments is very crucial for maintaining the accuracy of measurements. Before installation in the field, temperature and humidity sensors were calibrated in the laboratory. Further, these sensors along with a reference platinum resistance thermometer (Pt1000) were then placed in a closed, insulated chamber having a fan for air circulation, and data collected continuously over one diurnal cycle in the laboratory. This provided data to check the relative differences between similar sensors. The wind sensors (slow sensors) are calibrated using sonic anemometer as the reference by placing all of them at the same height on the tower. The sonic anemometer was independently calibrated earlier in a wind tunnel, and found to perform as per the manufacturer specifications.

\section{Theory}

Figure 1 shows a schematic of different terms involved in the land surface energy budget. The surface is assumed to have vegetation that forms the interface between the soil surface and the atmosphere. $S W_{\text {in }}$ and $S W_{\text {out }}$ are the incoming and reflected fluxes of shortwave radiation, $R_{\text {in }}$ and $R_{\text {out }}$ are respectively the incoming and outgoing fluxes of longwave radiation. Assuming horizontal homogeneity $\left(Q_{A}\right.$ is ignored) and neglecting the energy storage in the interfacial layer ( $S$ is neglected), the energy balance at the earth's surface gives,

$$
\begin{aligned}
S W_{\text {in }}= & S H F+L H F+S W_{\text {out }} \\
& +N L W+G, \\
R_{\text {net }}= & S W_{\text {in }}-S W_{\text {out }}-N L W=S H F \\
& +L H F+G,
\end{aligned}
$$

and

$$
\begin{aligned}
Q_{\mathrm{net}}= & S W_{\mathrm{in}}-\left(S W_{\mathrm{out}}+N L W\right. \\
& +S H F+L H F+G),
\end{aligned}
$$

where $N L W$ is net longwave radiation $\left(=R_{\text {out }}-\right.$ $\left.R_{\text {in }}\right)$. Here, $S W_{\text {in }}$ and $R_{\text {in }}$ directed towards while 
other components directed away from the surface are taken positive. Both equations (1a) and (1b) are identical, however, their interpretations are slightly different. Normally, when such equations are written, uncertainties are thought to be with the $R H S$. In the present case, putting $R_{\text {net }}$ on $L H S$ gives the impression that radiative fluxes are alright. This is far from the truth. There could be substantial errors in the radiation terms, longwave fluxes, in particular. To emphasize this, we consider equation (1a) along with the more traditional form, namely, equation (1b) which equates the net radiation to the sum of turbulent fluxes (SHF and $L H F$ ) and ground heat flux. Components of radiation can be measured using appropriate radiation instruments. $S H F$ and $L H F$ are estimated by assuming the flow to be stationary, turbulent and horizontally homogeneous. This leads to the expressions (e.g., Stull 1988):

$$
\left.\begin{array}{rl}
S H F & =\rho C_{p} \overline{w^{\prime} \theta^{\prime}}=-\rho C_{p} u_{*} \theta_{*} \\
L H F & =\rho L_{e} \overline{w^{\prime} q^{\prime}}=-\rho L_{e} u_{*} q_{*} \\
\tau & =-\rho \overline{u^{\prime} w^{\prime}}=\rho u_{*}^{2}
\end{array}\right\},
$$

where $\tau$ is the surface shear stress, $\rho$ is air density, $u_{*}, \theta_{*}$ and $q_{*}$ are respectively the surface layer scales for horizontal wind speed $(U)$, potential temperature $(\theta)$ and specific humidity $(q) . C_{p}$ is specific heat of air at constant pressure, $L_{e}$ is the latent heat of vaporization, $u$ and $w$ are the horizontal (along the mean wind direction) and vertical components of wind velocity respectively measured with a sensor having frequency response better than $1 \mathrm{~Hz}$. The prime denotes the fluctuating parts of respective variables and the overbar represents time averaging. The terms involving the covariances define the respective fluxes in a turbulent flow. With data from instruments that enable the measurements of turbulent fluctuations in the flow (i.e., fast sensors), covariances can be computed and fluxes obtained. The bulk methods vary in complexity, but nowadays are mostly based on $\mathrm{M}-\mathrm{O}$ similarity theory for a turbulent convective boundary layer (Dyer 1974; Hicks 1976; Beljaars and Holtslag 1991). The vertical profiles of time averaged quantities are given by (e.g., Panofsky and Dutton 1984):

$$
U=\frac{u_{*}}{k}\left[\ln \left(\frac{z}{z_{o_{m}}}\right)-\psi_{m}(\xi)\right]
$$

$$
\begin{aligned}
& \theta-\theta_{o}=\frac{\theta_{*}}{k}\left[\ln \left(\frac{z}{z_{o s}}\right)-\psi_{s}(\xi)\right] \\
& q-q_{o}=\frac{q_{*}}{k}\left[\ln \left(\frac{z}{z_{o s}}\right)-\psi_{s}(\xi)\right] .
\end{aligned}
$$

Here, $z$ is height above the surface, $z_{o m}$ and $z_{o s}$ are surface roughness lengths for velocity and scalar $(\theta$ and $q)$, respectively. The subscript $o$ refers to the value of the scalar at the roughness height $z_{o s} . \psi_{m}$ and $\psi_{s}$ are the $\mathrm{M}-\mathrm{O}$ similarity functions for $U$ and scalar respectively, and are functions of the stability parameter $\zeta(=z / L$, where $L$ is the Monin-Obukhov length scale). $\zeta<0,=0$ and $>0$ correspond to unstable, neutral and stable stratification respectively. $L$ is given by (Garratt 1992):

$$
L=\frac{\theta_{v} u_{*}^{2}}{g k \theta_{v *}} .
$$

$\theta_{v}$ is the virtual potential temperature, and $\theta_{v}$ and $\theta_{v *}$ are given by:

$$
\begin{aligned}
\theta_{v} & =\theta(1+0.61 r) \\
\theta_{v *} & =0.61 \theta q_{*}+\theta_{*}(1+0.61 r),
\end{aligned}
$$

where $r$ is the mixing ratio and is related to $q$ through the equation $r=q /(1-q)$. Both $r$ and $q$ are small $\left[\sim \mathrm{O}\left(10^{-2}\right)\right]$ and nearly equal. Functions $\psi_{m}$ and $\psi_{s}$ are empirically determined. The profile method (PM) is a special case of bulk method when measurements at two or more levels in the surface layer are available. For measurements at 2 levels, equations (3) can be rearranged to give:

$$
\begin{aligned}
& U_{2}-U_{1}=\Delta U=\frac{u_{*}}{k}\left[\ln \left(\frac{z_{2}}{z_{1}}\right)-\psi_{m}\left(\xi_{2}\right)+\psi_{m}\left(\xi_{1}\right)\right] \\
& \theta_{2}-\theta_{1}=\Delta \theta=\frac{\theta_{*}}{k}\left[\ln \left(\frac{z_{2}}{z_{1}}\right)-\psi_{s}\left(\xi_{2}\right)+\psi_{s}\left(\xi_{1}\right)\right] \\
& q_{2}-q_{1}=\Delta q=\frac{q_{*}}{k}\left[\ln \left(\frac{z_{2}}{z_{1}}\right)-\psi_{s}\left(\xi_{2}\right)+\psi_{s}\left(\xi_{1}\right)\right]
\end{aligned}
$$

where, $\xi_{1}=z_{1} / L$ and $\xi_{2}=z_{2} / L$, and the subscripts 1 and 2 refer to lower and upper measurement levels respectively. If wind, temperature and 
humidity data are available at 2 levels, then, equations (4)-(6) can be solved (iteratively) to obtain $u_{*}, \theta_{*}$ and $q_{*}$ which when used with equation (2) give $S H F$ and $L H F$. Note that this method does not assume a drag (or exchange) coefficient. The $\mathrm{M}-\mathrm{O}$ similarity functions used in this work are based on the works of (Dyer 1974; Beljaars and Holtslag 1991) and are given in Appendix 1.

\subsection{Eddy Correlation Method (ECM)}

The terms involving the covariances in equation (2) define the respective fluxes in a turbulent flow, and the method of calculating fluxes through computing covariances is known as ECM. With sonic anemometer data sampled at $10 \mathrm{~Hz}$, it is possible to compute the covariances and calculate fluxes. Implicit assumption in ECM is that the flow is stationary which is not the case in the atmosphere a majority of the time. The fluxes calculated using ECM are reliable if the flow remains stationary over a time interval of at least 15-30 minutes, and the fluctuating quantities are based on the averages taken over this time interval. Strict stationarity is rarely satisfied in the atmosphere. Statistical tests can be applied to determine if the flow is stationary. This is usually done by dividing the averaging time into two equal parts and calculating the mean and the standard deviation for the two intervals. Then student's t and F tests are applied to the means and standard deviations respectively to determine if the time series satisfies stationarity (e.g., Bendat and Piersol 1986). For the averaging time of 20 minutes used in this study and for the flow conditions that prevailed during a majority time of the observations, $95 \%$ confidence limit was satisfied if the means and standard deviations in the two intervals were within $5 \%$ of each other. Therefore, we used the simple criteria that if both the mean and standard deviations are within 5\% of each other when calculated for each half of the averaging time interval separately, then the flow is stationary.

In the application of ECM, sensor alignment is very critical (Wilczak et al 2001). Ideally, the tower site should be on level ground and homogeneous, and the vertical axis of the sonic anemometer parallel to normal to the surface. In this perfectly aligned system, the vertical component of velocity averaged over about half an hour is close to zero. Perfect alignment is very difficult to achieve in the field. If the vertical axis is tilted, then the measured vertical velocity includes a component of the horizontal velocity which causes significant errors in the fluxes computed by ECM. The alignment can be checked by plotting the mean vertical velocity against the mean horizontal wind speed

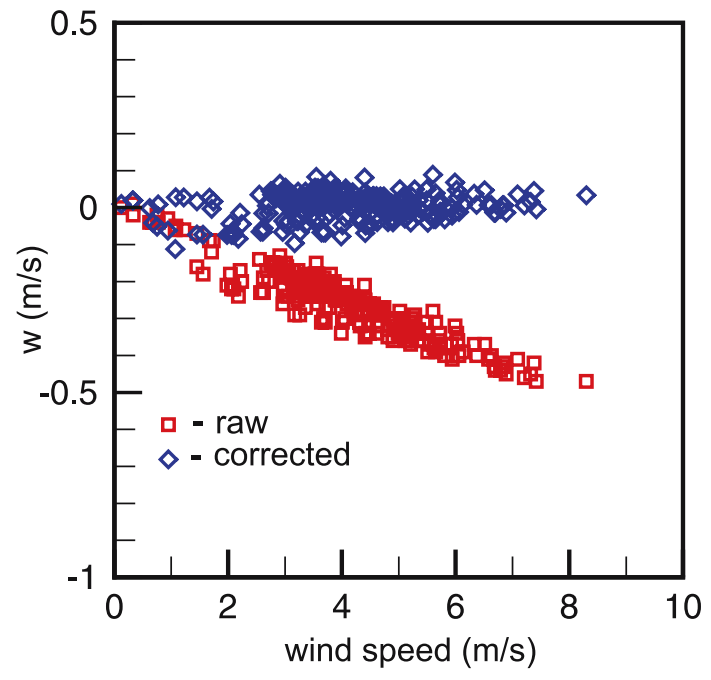

Figure 3. Variation of the 30-minute average vertical velocity $(w)$ with the horizontal wind speed, both measured by the sonic anemometer. Raw and corrected refer to uncorrected and corrected vertical velocity.

(figure 3). Any systematic trend implies that the vertical alignment is not perfect, and this is the case in figure 3 implying that the measured vertical velocity was not normal to the mean streamlines. The vertical inclination works out to be $3.6^{\circ}$ at an azimuthal angle of $258^{\circ}$ from north. This could have resulted from ground slope or sensor inclination. If this was due to terrain, then, the terrain height should have changed by $1 \mathrm{~m}$ for every $16 \mathrm{~m}$ horizontal distance. Visual inspection of the ground shows that the ground slope is much less than this. Hence, we primarily attribute the cause to sensor inclination. By a co-ordinate rotation, the true vertical velocity can be obtained. The wind vector was corrected accordingly (figure 3) before calculating the fluxes by ECM. The difference between the fluxes computed from ECM with and without correction for the vertical tilt is found to be about $20 \%$ with uncorrected values being larger.

\section{Results}

\subsection{Mean conditions}

The time series of daily average $T, q, U$, soil temperature and rainfall are shown in figure 4 . Seasonal trends as well as fluctuations on synoptic (i.e., few days) to monthly (i.e., intra-seasonal) time scales are observed. The mid and later half of May had few showers and the daily rainfall exceeded $20 \mathrm{~mm}$ on a couple of occasions. Between mid May and June beginning, air and soil temperatures decreased by $5-7^{\circ} \mathrm{C}$ and $q$ increased by about $4 \mathrm{~g} \mathrm{~kg}^{-1}$. It is observed from figure 4 that the 

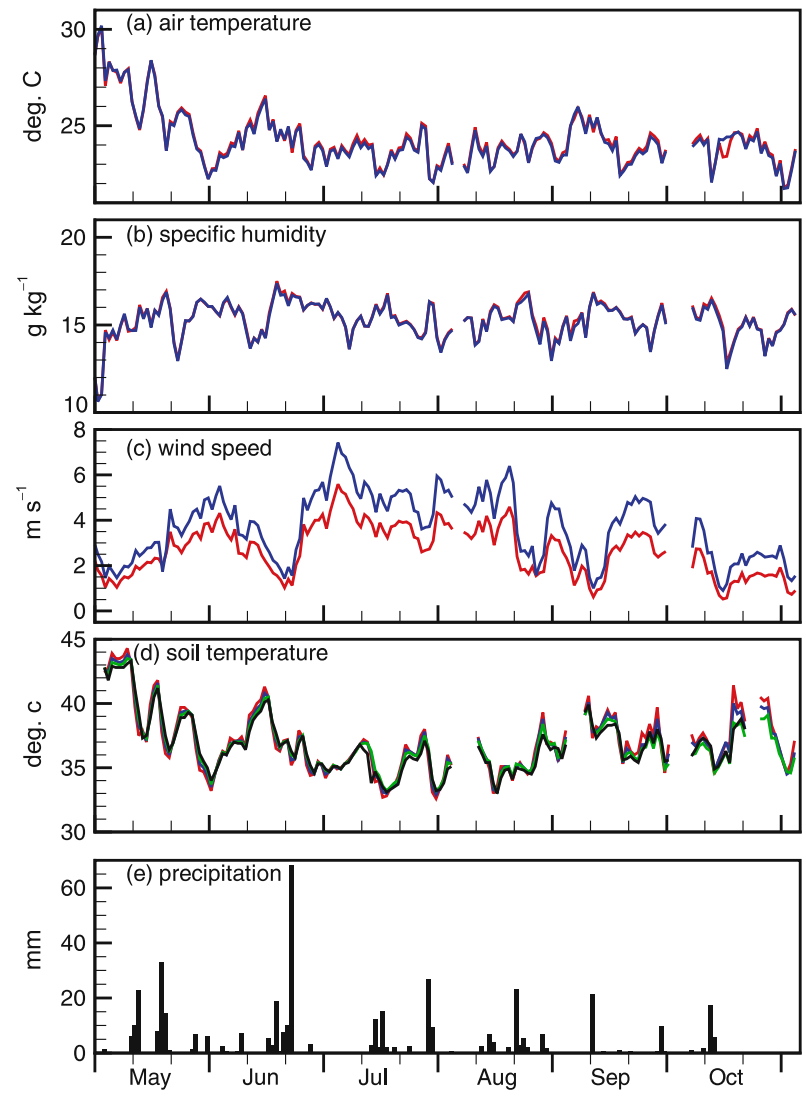

Figure 4. Temporal variation of the daily average values of (a) air temperature, (b) specific humidity, (c) wind speed, (d) soil temperature at 0.05, 0.1, 0.15 and $0.2 \mathrm{~m}$ depths, and (e) precipitation.

differences in temperatures and specific humidities between 2 and $8 \mathrm{~m}$ heights are very small on most days [note that these small differences matter in flux calculations, see equation (6)], whereas, that in wind speed is clearly discernible. Wind speeds are higher during the summer monsoon period. The wind speed at $2 \mathrm{~m}$ height remained below $5 \mathrm{~m} \mathrm{~s}^{-1}$ throughout the observation period while that at $8 \mathrm{~m}$ height is larger and the maximum value exceeded $7 \mathrm{~m} \mathrm{~s}^{-1}$. Soil temperature between 0.05 and $0.2 \mathrm{~m}$ is nearly uniform for a majority of the time. On monthly and seasonal time scales, the change in soil temperature is small. This provides a constraint to the surface energy budget (discussed later). The peak monsoon season in Bangalore is during August-October. The number of rainy days was several during this period (figure 4e), however, most of the rain events were weak and only on three occasions rainfall around $20 \mathrm{~mm}$ day $^{-1}$ occurred. Fraction of the total time when it actually rained is only $1.1 \%$. The annual rainfall measured in the IISc campus in the year 2006 was $632 \mathrm{~mm}$, very low when compared to that of $2004(1081 \mathrm{~mm})$ and $2005(1442 \mathrm{~mm})$. Thus, the study year was relatively dry.

\subsection{Further refining variables and fluxes}

With the measurements available at 2 levels, $S H F$ and $L H F$ are calculated using equations (4)-(6). The initial values did not appear alright. For example, calculated $L H F$ was as large as $-100 \mathrm{~W} \mathrm{~m}^{-2}$ during some nights but the atmosphere was dry. Similarly, SHF exceeded $-100 \mathrm{~W} \mathrm{~m}^{-2}$ during nights and day time values exceeded $600 \mathrm{~W} \mathrm{~m}^{-2}$. To check if sensors retained the initial calibration or not, temperature and humidity sensors were brought back to the laboratory and calibrated again. There was no degradation in the performance of the sensors. With calibration, the uncertainty in the temperature of each sensor can be reduced to $0.1^{\circ} \mathrm{C}$ and that in $R H$ to around $1 \%$. These values are smaller than the usual manufacturer specified accuracy levels (which are typically not better than $0.2^{\circ} \mathrm{C}$ and $1.5 \%$ for $T$ and $R H$ respectively, table 1$)$. In the profile method, calculated fluxes are very sensitive to even small systematic biases between the sensors. Calculations show that even after careful calibration, uncertainties in $S H F$ and $L H F$ remain high (20\% or larger). To further reduce the inherent instrument differences, wind, temperature and humidity sensors were mounted at the same height $(8 \mathrm{~m})$ and data collected continuously for few days. There were small but systematic differences between the two sensors measuring the same variable. The constants of the sensors at $2 \mathrm{~m}$ height were fine tuned to match the values measured by the sensor mounted at $8 \mathrm{~m}$ level for the intercomparison period. Further, it was observed that the response of the humidity sensor at $2 \mathrm{~m}$ height is non-linear above $86 \% R H$ (figure 5a), and a look-up table was prepared for $R H>86 \%$ to convert measured voltage into $R H$ for this sensor. After the corrections, the rms values of $\Delta R H\left(=R H_{2}-R H_{1}\right)$ and $\Delta T\left(=T_{2}-T_{1}\right)$ are $0.23 \%$ and $0.04^{\circ} \mathrm{C}$ respectively (figure $5 \mathrm{c}-\mathrm{d}$ ). Thus, with the help of laboratory calibration and intercomparison exercises, the systematic differences between respective sensors were brought down to levels well below the manufacturer specified accuracies.

Despite all these efforts, values of $S H F$ exceeded $-100 \mathrm{~W} \mathrm{~m}^{-2}$ on some occasions (figure 6a). These cases were examined in detail to understand the reasons for the large and negative values of $S H F$. A representative time series of $S H F, \Delta T$ and $u$ for such cases are shown in figure 6 . Often, the low values of $S H F$ occurred under calm conditions during night time. Air was more or less still at $2 \mathrm{~m}$ height and about 0.5 to $1 \mathrm{~m} \mathrm{~s}^{-1}$ at $8 \mathrm{~m}$ height, and $\Delta T$ values were as large as $-2^{\circ}$ to $-3^{\circ} \mathrm{C}$ (figure $6 \mathrm{c}$ ). This resulted in large negative values in $S H F$ since only the difference between the wind speeds at 2 levels appears in equation (6) and not the magnitudes 

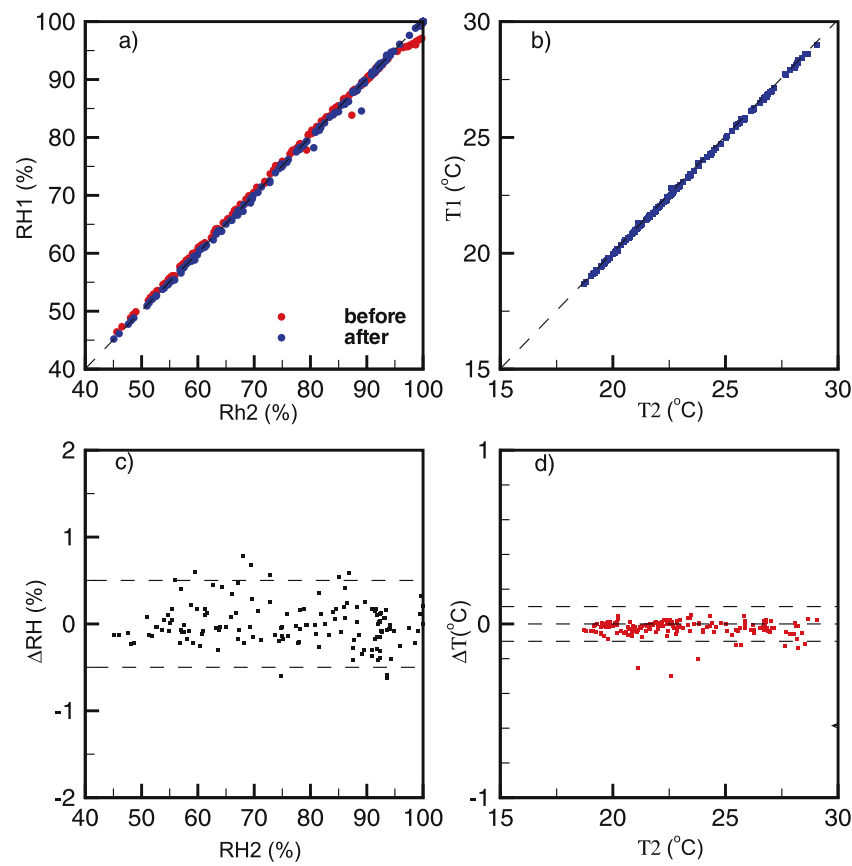

Figure 5. Comparison of relative humidity and air temperature measured by the respective sensors during the intercomparison period. Data are 20-minute averages. 1 and 2 refer to measurement levels. (a) relative humidity, (b) air temperature, (c) $\Delta R H$ vs. $R H$, and (d) $\Delta T$ vs. $T$. In panel a), before and after refer to $R H$ measured by the sensor installed at $2 \mathrm{~m}$ height before and after the corrections.

of the wind speeds. The implicit assumption in deriving equation (6) is that the boundary layer is turbulent and convective. This assumption breaks down during calm clear nights.

Therefore, it became clear that the problem arises during the night time under low wind conditions where still atmosphere is occasionally interrupted by (mild) wind bursts (Nakamura and Mahrt 2005). For this case, $\mathrm{M}-\mathrm{O}$ similarity theory is not applicable and the estimation of $L H F$ and $S H F$ under such conditions remains a major challenge as stated in the introduction. The problem is not trivial because there is no independent method of measuring $S H F$ and $L H F$ in the field other than through the measurements of wind speed, temperature and water vapour, and under the assumption that the flow is stationary. For the present purpose, hoping that comparing fluxes from two different methods may provide some hints, we compared the PM based fluxes with those based on ECM. One important fact to be noted in this comparison is that sonic anemometer measures the virtual temperature $T_{v}$ (temperature that accounts for the effect of water vapour on air density) and not the actual air temperature $T . T_{v}$ is given by (Garratt 1992, p 22).

$$
T_{v}=(T+273.16)\left(1+0.608^{*} r\right)-273.16 .
$$
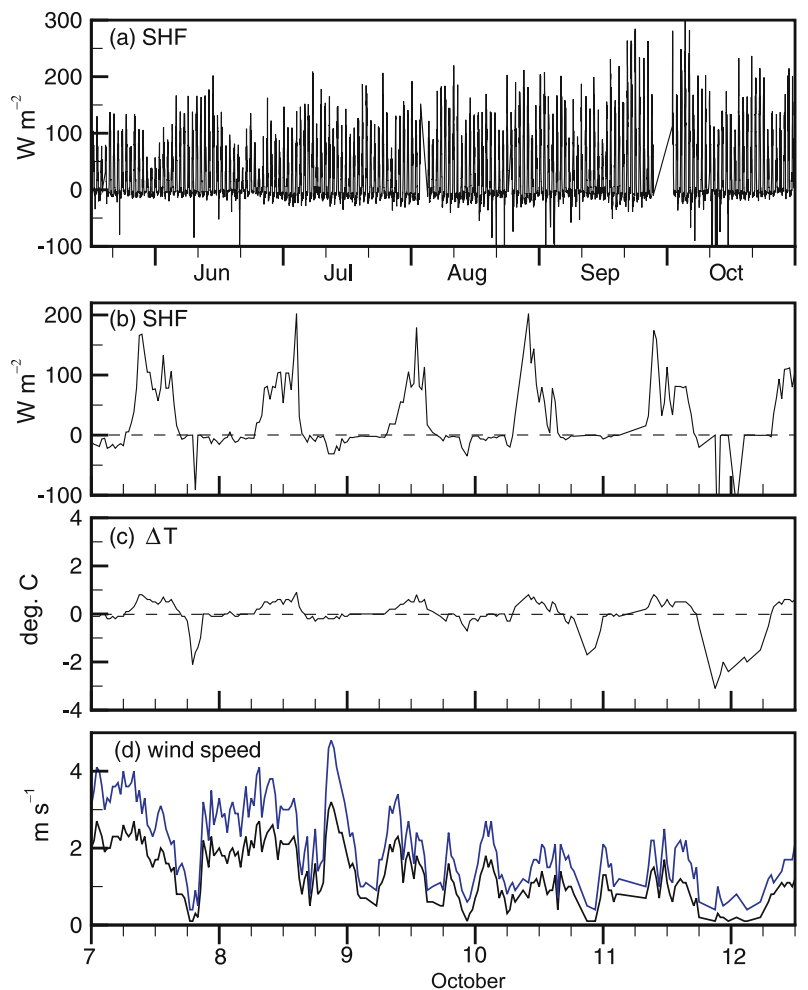

Figure 6. (a) Temporal variation of $S H F$ during the study period. Panels (b)-(d) show the variation of $S H F, \Delta T$ and wind speed during 7-12 October 2006. Note that wind speed at level 2 is larger.

Here $T_{v}$ is in degree Celsius. Therefore the correlation $\rho C_{p} \overline{w^{\prime} \theta_{s}^{\prime}}$ [where $\theta_{s}$ is the potential temperature based on sonic temperature $T_{v}$, see equations (2) and (5)] is not conventional SHF. For the convenience of reference, henceforth it is denoted by $S H F_{v}$. The corresponding flux calculated using PM is given by $S H F_{v}=\rho C_{p} u_{*} \theta_{v *}$ [where $\theta_{v *}$ is defined in equation (5)]. The values of $S H F_{v}$ were calculated for an averaging time of $1200 \mathrm{~s}$. For the entire sonic anemometer time series data collected during June-July 2006 (with data gaps), only 422 data stretches satisfied the stationarity conditions. Among these, wind speed below $1 \mathrm{~m} \mathrm{~s}^{-1}$ occured in only one case. In order to increase the number of data points below $2 \mathrm{~m} \mathrm{~s}^{-1}$, sonic data time series was high band pass filtered to remove slowly varying components having time periods of more than 5 minutes (the reason being, major contribution to turbulent flux comes from frequencies higher than that corresponding to 5-minute periods, e.g., Nakamura and Mahrt 2005). The fluxes are calculated for the filtered data for each 20-minute interval. For the same averaging time interval, $S H F_{v}$ is calculated using PM.

The outcome of this exercise is shown in figure 7 . This figure also shows a comparison of the wind speeds measured at $2 \mathrm{~m}$ height by sonic and 

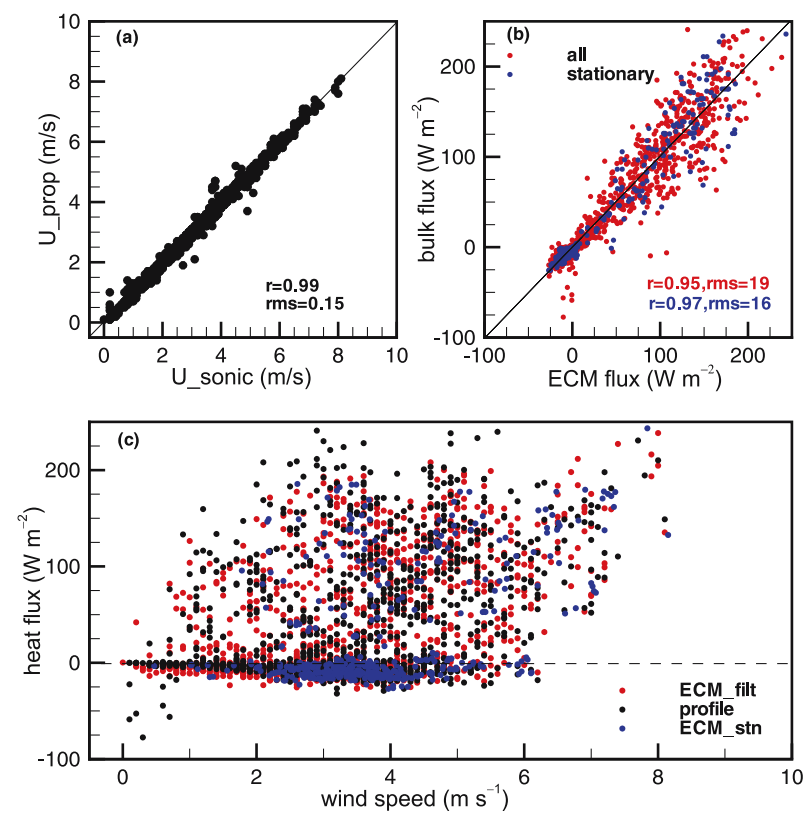

Figure 7. (a) Comparison of wind speeds measured by sonic and propeller anemometers at $2 \mathrm{~m}$ height. (b) Comparison of $S H F_{v}$ from ECM and PM. (c) Variation of $S H F_{v}$ with wind speed at $2 \mathrm{~m}$ height. Correlation coefficient $(r)$ and rms errors (in respective units) are shown in panels (a) and (b). ECM_filt and ECM_stn refer to ECM fluxes for filtered and stationary time series.

propeller anemometers. In figure $7(\mathrm{~b}), S H F_{v}$ calculated from PM is plotted against those calculated from ECM for stationary and filtered time series. There is no noticeable bias or trend between the fluxes from the two methods for both the time series for positive values of $S H F_{v}$. However, a major difference is observed at negative values of $S H F_{v}$. This occurs in the low wind regime (figure $7 \mathrm{c}$ ). $S H F_{v}$ from ECM calculated for stationary time series did not go below $-10 \mathrm{~W} \mathrm{~m}^{-2}$ at wind speeds less than $2 \mathrm{~m} \mathrm{~s}^{-1}$ during night times. However, the number of data points in this wind speed range is too few to draw statistically significant conclusions. The number of data points are more for fluxes based on filtered time series, and if negative values of $S H F_{v}$ are only considered, the average value of $S H F_{v}$ is $-12 \mathrm{~W} \mathrm{~m}^{-2}$ for wind speed around $2 \mathrm{~m} \mathrm{~s}^{-1}$ and approach zero for wind speeds below $0.1 \mathrm{~m} \mathrm{~s}^{-1}$. On the other hand, $S H F_{v}$ based on the bulk method shows some large negative values for wind speeds below $1 \mathrm{~m} \mathrm{~s}^{-1}$. As explained earlier, $\mathrm{M}-\mathrm{O}$ similarity theory is not applicable for these cases. Therefore, if the wind speed at $2 \mathrm{~m}$ level is less than $2 \mathrm{~m} \mathrm{~s}^{-1}$ and $S H F_{v}$ goes below $-12 \mathrm{~W} \mathrm{~m}^{-2}$, then it seems reasonable to replace this by a value between $-12 \mathrm{~W} \mathrm{~m}^{-2}$ and zero depending on the wind speed (by a linear regression).

Finally, what we need is $S H F$ and not $S H F_{v}$ for heat budget calculations. Comparing $S H F$ and
$S H F_{v}$ (both by PM) showed that the two differ from each other by less than a $\mathrm{W} \mathrm{m}^{-2}$ if the absolute value of $S H F_{v}$ is less than $50 \mathrm{~W} \mathrm{~m}^{-2}$. Therefore, we extend the results obtained for $S H F_{v}$ to $S H F$ if the wind speed at $2 \mathrm{~m}$ level is below $2 \mathrm{~m} \mathrm{~s}^{-1}$ and the flux is negative. Same criterion is applied to $L H F$ as well.

\subsection{Surface energy balance}

In order to understand the relative importance of different components involved in the surface energy balance, we present the energy source and sink terms separately. In the following, $S W_{\text {in }}$ is taken as the energy source and the terms on the right hand side in equation (1a) together are taken as the energy sink. Traditionally, equation (1b) is used to look at the surface energy imbalance. For reasons stated in section 3 , we show results for both equations in the following. Thus, the cumulative average source and sink are (ignoring the contribution of ground heat flux $G$ ),

$$
\left.\begin{array}{rl}
\text { Source }= & \frac{1}{n} \sum_{i=1}^{n}\left(S W_{\mathrm{in}}\right)_{i} \\
\text { Sink }= & \frac{1}{n} \sum_{i=1}^{n}(S H F+L H F \\
& \left.+N L W+S W_{\mathrm{out}}\right)_{i}
\end{array}\right\},
$$

where $i$ refers to time. For calculating the source and sink in equation (8), LHF and SHF are estimated taking 30-minute averaged values and radiative fluxes are also averaged over the same time interval (giving 48 values per day). The resulting fluxes are added up and the average is taken. Since $S W_{\text {in }}$ has strong diurnal dependence, missing data can lead to biases in the cumulative average. Therefore, only those days with complete 24-hour data are considered while calculating the summations in equation (8). The integration started from May 15. Owing to strong diurnal variation in $S W_{\text {in }}$, source shows large amplitude fluctuations initially and it takes few days before its diurnal fluctuations subside. Figure 8(a) shows the temporal variation of individual terms in the sink, and source and sink are compared in figure 8(b) and figure 8(c) shows $R_{\text {net }}$ and $T F$.

During the May-October period, the largest among the sink terms is $N L W$ with an average value 

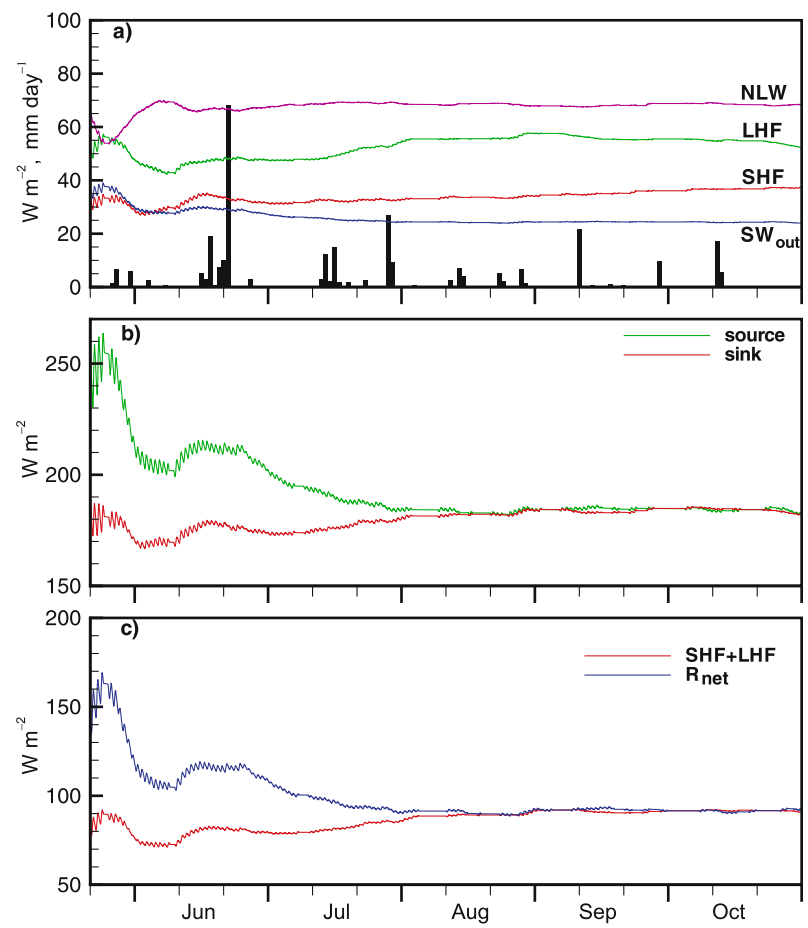

Figure 8. (a) Temporal variation of components of energy equation. Also shown in the same panel is daily rainfall. (b) Variation of source and sink. (c) $R_{\text {net }}$ and $T F$. Note that the values shown here are cumulative average values.

of $68 \mathrm{~W} \mathrm{~m}^{-2}$, followed by $L H F$ with an average value of $52 \mathrm{~W} \mathrm{~m}^{-2}, S H F$ is third at $37 \mathrm{~W} \mathrm{~m}^{-2}$ and the smallest term is $S W_{\text {out }}$ at $24 \mathrm{~W} \mathrm{~m}^{-2}$. Owing to (intermittent) rains, soil had moisture and a substantial part of the energy came out in the form of water vapour. This could be a feature over the land surface during the monsoon. We were expecting $S H F$ to be the dominant component over the land surface, but this is not the case. The sum of the two radiative components $\left(92 \mathrm{~W} \mathrm{~m}^{-2}\right)$ and sum of $S H F$ and $L H F\left(89 \mathrm{~W} \mathrm{~m}^{-2}\right)$ are nearly equal (the difference is within experimental error), i.e., the energy loss through radiative processes is as large as that due to the turbulent fluxes $(T F)$.

Both figures 8(b) and 8(c) show similar trends and differences are mainly in the magnitudes. Therefore, we discuss figure 8(b) here and the same applies to figure 8(c) as well. The sink is more or less steady and its seasonal variation is relatively small (168 to $188 \mathrm{~W} \mathrm{~m}^{-2}$ and settles around $180 \mathrm{~W} \mathrm{~m}^{-2}$ from August onwards), whereas the source is around $250 \mathrm{~W} \mathrm{~m}^{-2}$ during late May, and gradually decreases to around $180 \mathrm{~W} \mathrm{~m}^{-2}$ as the monsoon season progressed. If we consider the period May-July, source is larger than sink (figure 8b). Before the monsoon onset, there is a large gap between source and sink and during the second half of May the average difference between them is $65 \mathrm{~W} \mathrm{~m}^{-2}$, i.e., larger than the individual
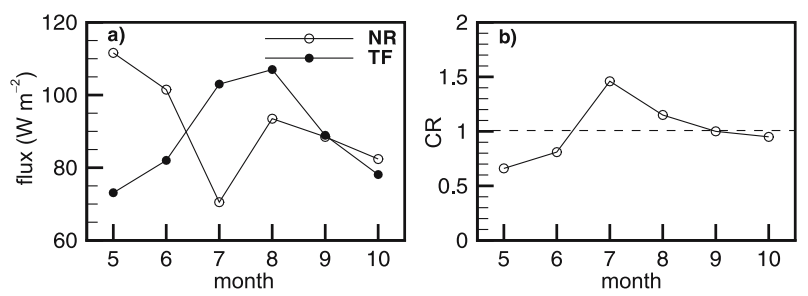

Figure 9. (a) The variation of monthly average net radiation and turbulent fluxes during May-October. May average is based on observations made during 15-31 May. (b) Monthly variation of the closure ratio. The dashed line indicates a $C R$ value of unity where energy gained through net radiation is lost through turbulent fluxes.

sink terms during this period (figure 8a). The average soil temperature decreased from around $41^{\circ} \mathrm{C}$ to $34^{\circ} \mathrm{C}$ during this period (figure 4 ), and thus ground also lost heat. During June also imbalance remained but reduced to around $25 \mathrm{~W} \mathrm{~m}^{-2}$. The differences between source and sink are about $26 \%$ and $10-12 \%$ of the source term during May and June respectively. Soil temperature did increase during the first half of June, but the increase was arrested after the second week and temperature started falling and the net change during the month is small (figure 4d). In equation (1), the contribution from precipitation has been neglected. Since the amount of precipitation has been measured, it is possible to estimate the contribution from it. Calculations show that the contribution from rainfall is not more than a few $\mathrm{W} \mathrm{m}^{-2}$. Therefore, the energy imbalance during May-June cannot be attributed to ground heat flux and precipitation. Whether advection was so large or not, cannot be answered from the present experimental arrangement.

Figure 9 shows the monthly variation of $T F$ and $R_{\text {net }}$ and the closure ratio $C R\left(=T F / R_{\text {net }}\right) . T F$ is minimum during May, increases subsequently and peaks during August. $R_{\text {net }}$ is maximum during May and minimum during July. $C R$ value of more than unity means that more energy is lost due to turbulent fluxes than received through net radiation.

\section{Discussion and conclusion}

The present study covers the period second half of May to October end. It would have been nice to study the surface energy balance during the transition from winter to summer months too where $L H F$ is expected to be small. In fact, the tower installation started in November 2005; however, it took six months to get all measurements in order to obtain continuous data. The present set of measurements and analysis have given ideas about the problems to be overcome, both instrument and 


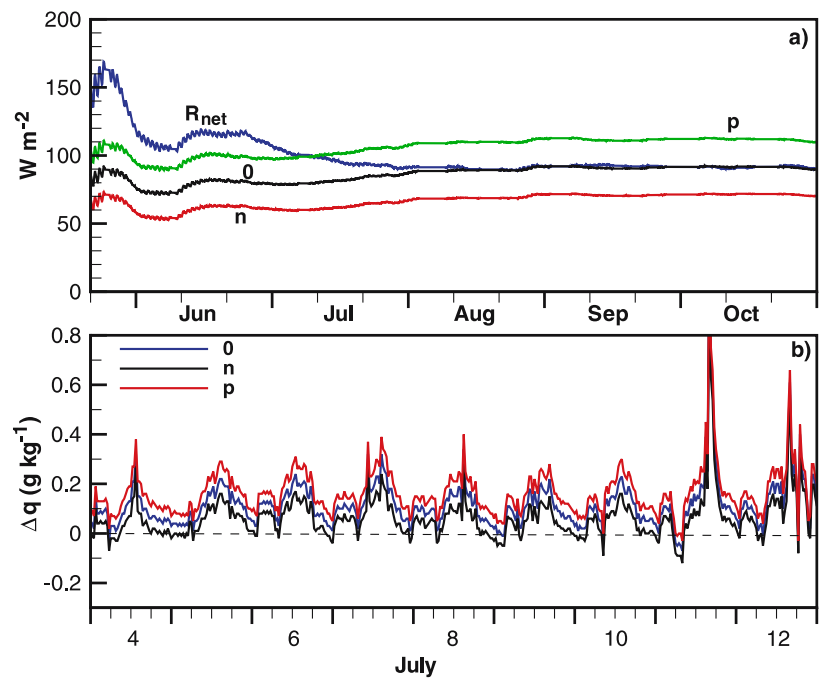

Figure 10. (a) Sensitivity of $T F$ to variation in $\Delta R H$. (b) The temporal variation of $\Delta q .0, n$ and $p$ refer to $0,-0.25 \%$, and $+0.25 \%$ perturbations to $\Delta R H$.

theory related, when attempting surface energy balance on seasonal time scales using slow sensor data. The stably stratified low wind cases are frequent over land and ways to obtain fluxes during such conditions need to be devised and standardized. One important result from the present study is the large contribution of the net longwave radiation to surface energy budget. In the Indian field programmes, measurement of longwave radiation has not been given high priority so far, and going by the present results, it is important that both shortwave and longwave radiation are measured accurately. This point needs emphasis because there are several programmes in the country where detailed boundary layer measurements are being planned using instrumented towers. This includes the STORM (Severe Thunderstorms Observations and Regional Modeling) in the northeastern India, PROWNOM (Prediction of Regional Weather with Observational Meso-Network and Atmospheric Modeling) in south India and CTCZ (Continental Tropical Convergence Zone) in north India. If these efforts are to yield scientifically valuable results, then issues related to the selection of sensors, measurement accuracy, calibration and on site intercomparison, are to be adequately addressed. It is hoped that the present study provides useful information to those planning to make tower measurements with instruments at multi-levels.

It is important to understand how sensitive the energy closure is to errors/uncertainties in $\Delta T$ and $\Delta R H$. It is noted in the previous section that the rms values of $\Delta R H$ and $\Delta T$ are $0.23 \%$ and $0.04^{\circ} \mathrm{C}$ respectively. We changed $\Delta R H$ and $\Delta T$ by $\pm 0.25 \%$ and $\pm 0.05^{\circ} \mathrm{C}$ respectively (i.e., comparable
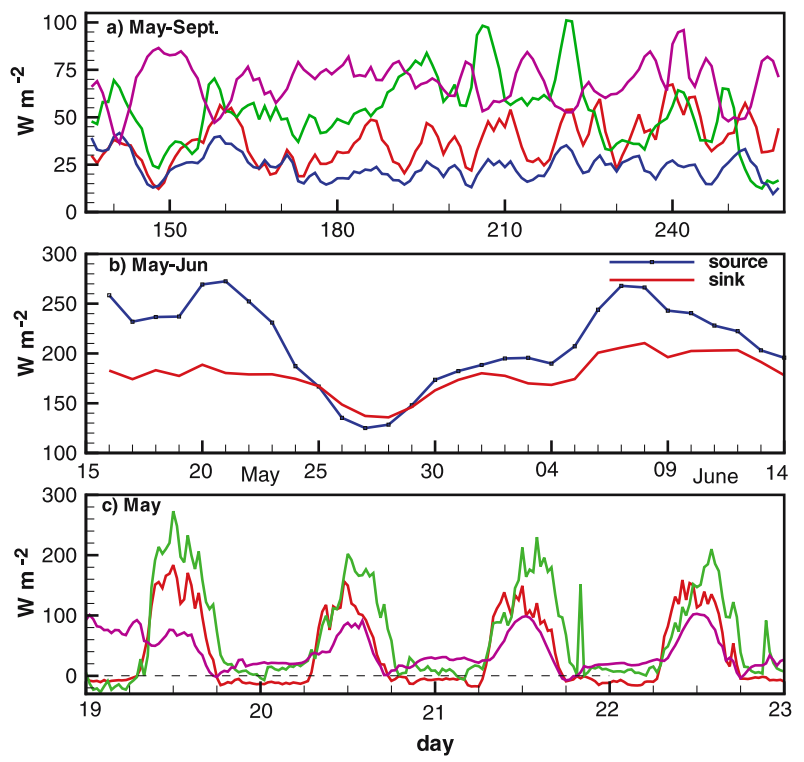

Figure 11. Components of surface heat flux. (a) $S H F$ (red), $L H F$ (green), $N L W$ (pink) and $S W_{\text {out }}$ (blue) for May-October period. Days with missing data have been removed and $x$-axis initially represents the Julian day but after day 180, successive days with data. (b) Source and sink terms. (c) $S H F$ (red), $L H F$ (green) and $N L W$ (pink) during 19-22 May. Fluxes in (a) and (b) are 3-day running average values whereas in (c) is 30-minute average.

to respective rms difference) and examined the changes in $S H F$ and $L H F$ (radiative components remain the same). There is little change in $S H F$ and $L H F$ for the specified change in $\Delta T$. However, when $\Delta R H$ is perturbed by $\pm 0.25 \%$, the change in $L H F$ is about $20 \mathrm{~W} \mathrm{~m}^{-2}$ (figure 10 a), i.e., comparable to the contribution of $S W_{\text {out }}$ (figure 8a). The reason for the large impact of $R H$ is that the magnitude of $\Delta q$ is less than $0.3 \mathrm{~g} \mathrm{~kg}^{-1}$ a majority of the time (figure 10b) and the perturbations caused in $\Delta q$ due to the above changes in $\Delta R H$ are about $\pm 0.06 \mathrm{~g} \mathrm{~kg}^{-1}$, which is a significant fraction of $\Delta q$.

One question that naturally arises after an examination of figure 8 is, why the budget does not close during the pre-monsoon period but does so during August-October months? Is it because the terms neglected were important during the premonsoon period, or calibration drifted, or due to errors in measurement or in flux algorithms? We don't have a satisfactory answer to all these questions, however, there is no harm in looking at the components of the fluxes during the period when the difference between source and sink are the largest. This happened during 15-23 May with the difference peaking $\left(\sim 90 \mathrm{~W} \mathrm{~m}^{-2}\right)$ on $20-21$ May (figure 11). Soil temperature increased at a rate of little over a degree Celsius per day during 20-22 May (figure 4). The corresponding estimated ground heat flux is about $30 \mathrm{~W} \mathrm{~m}^{-2}$ [assuming that 
the top $1.5 \mathrm{~m}$ layer of the soil is uniformly heated, a soil density of $1500 \mathrm{~kg} \mathrm{~m}^{-3}$ (measured) and soil specific heat of $1200 \mathrm{~J} \mathrm{~kg}^{-1} \mathrm{~K}^{-1}$ (Farouki 1986)]. This roughly accounts for one third of the difference between source and sink.

The daily average value of $S W_{\text {in }}$ is the highest during $20-22$ May $\left(\sim 270 \mathrm{~W} \mathrm{~m}^{-2}\right.$, figure $\left.11 \mathrm{~b}\right)$ compared to any other day during the entire study period. Theoretically calculated daily average solar insolation at the top of the atmosphere is more than $440 \mathrm{~W} \mathrm{~m}^{-2}$ for the month of May for Bangalore latitude. Therefore, there is no reason to doubt $S W_{\text {in }}$ data for these days which were generally cloud free. The diurnal variations in $S H F$, $L H F$ and $N L W$ are shown in figure 11(c). The lowest value of $N L W$ during May-October period occurred around 20 May (figure 11a). On these days, values of $N L W$ just after the sunset reduced to zero, whereas, during say, August or September, the lowest value of $N L W$ is about $30 \mathrm{~W} \mathrm{~m}^{-2}$ (figure not shown). It is not clear why $N L W$ was so low around 20 May. Further, both LHF and SHF are either very small or negative at night time. The wind speed (at $2 \mathrm{~m}$ height) was in $2-4 \mathrm{~m} \mathrm{~s}^{-1}$ range even during the night time; therefore these were not calm nights to produce a very stable surface layer. A careful analysis of data under similar synoptic conditions is needed to check if the negative turbulent fluxes are real or due to sensor drift. As pointed out earlier in this section, drifts in the humidity sensor is very critical to $L H F$ estimation and even a small change of $0.25 \%$ in $\Delta R H$ can lead to $20 \mathrm{~W} \mathrm{~m}^{-2}$ change in $L H F$. It may be noted that detailed inter-comparison was carried out towards the end of September. However, now there is no way of knowing the extent of drift between May and September, if there was any. One way to overcome such problems in future is to carry out the intercomparison exercises more frequently and have more than one set of sensors at each level (to avoid data loss during intercomparisons). Further studies with regular intercomparisons and covering an entire year will provide insights into the missing elements in the surface energy balance.

To summarize, this is the first experiment carried out in India that addressed the surface energy balance on a seasonal time scale. It is shown that with a combination of laboratory calibration and field intercomparisons, measurement accuracies in temperature and relative humidity can be substantially improved over the manufacturer specifications. Important findings are as follows:

- When seen on the seasonal time scale, the net longwave radiation is the largest energy loss term at the experimental site.
- A bias of $0.25 \%$ in the relative humidity difference between the two levels results in about $20 \mathrm{~W} \mathrm{~m}^{-2}$ change in the latent heat flux. To achieve this level of accuracy, laboratory calibration and field intercomparison are required.

- The seasonal variation in the energy sink term is small compared to that in the energy source term.

\section{Acknowledgements}

The sensors and instruments used in this experiment were purchased from the funds provided by the Department of Science and Technology, New Delhi during BOBMEX (1999) and ARMEX (2002-05). The space to install the tower in the IISc Air Field was provided by the Department of Aerospace Engineering, IISc. L Prashanth Rao, J V S Raju and the workshop staff at the Centre for Atmospheric and Oceanic Sciences helped in setting up the tower and in data collection. Critical comments by an anonymous reviewer improved the overall scientific/technical content of the paper. We thank them all.

\section{Appendix 1}

The following similarity functions are used in the calculation of fluxes.

Unstable case: Dyer (1974):

$$
\begin{aligned}
\psi_{m}= & 2 \ln \left[\frac{(1+x)}{2}\right]+\left[\frac{\left(1+x^{2}\right)}{2}\right]-2 \tan ^{-1}(x) \\
& +\frac{\pi}{2} \quad\{-0.01>\xi>-2\} \\
\psi_{h, q}= & 2 \ln \left[\frac{\left(1+x^{2}\right)}{2}\right] \quad\{-0.01>\xi>-2\} \quad(\text { A. } 2)
\end{aligned}
$$

where $x=(1-16 \xi)^{1 / 4}$.

Stable case: Hicks (1976):

$$
\psi_{m}=\psi_{h, q}=-5 \xi, \quad\{3 \geq \xi \geq 0\} .
$$


Beljaars and Holtstag (1991):

$$
\begin{aligned}
-\psi_{m}= & a \xi+b\left(\xi-\frac{c}{d}\right) \exp (-d \xi) \\
& +\frac{b c}{d} \quad\{7 \geq \xi \geq 3\} \\
-\psi_{h, q}= & \left(1+\frac{2}{3} a \xi\right)^{3 / 2}+b\left(\xi-\frac{c}{d}\right) \exp (-d \xi) \\
& +\frac{b c}{d}+1 \quad\{7 \geq \xi \geq 3\}
\end{aligned}
$$

where $a=1, b=0.667, c=5$, and $d=0.35$.

For strongly stable stratification cases, MoninObukhov theory has limitations. In fact, there is large scatter between theoretical fits and observed data and it is for the user to believe which one is better. Introduction of additional length scales in addition to $L$, namely, $L_{f}$ characterizing the effect of earth's rotation and $L_{N}$ characterizing the non-local effect of the static stability in the free atmosphere reduce the scatter (Zilitinkevish and Esau 2007). However, to implement these scales, additional information is required (vertical profile of the atmosphere) which is not available at places having only tower measurements.

\section{References}

Anthoni P, Law B E and Unsworth M J 1999 Carbon and water vapor exchange of an open-canopied ponderosa pine ecosystem; Agric. For. Meteorol. 95 151-168.

Beljaars A C M and Holtslag A A M 1991 Flux Parameterization over Land Surfaces for Atmospheric Models; J. Appl. Meteor. 30 327-341.

Bendat J S and Piersol A G 1986 Random data analysis and measurement procedures; 2nd edn., John Wiley \& Sons.

Bhat G S, Rao P L, Sangolli V G, Bhat G P, Chandelkar A B, Rao H and Kadav V B 2005 Diurnal and intraseasonal variations observed on the west coast of India; Mausam 56 97-106.

Bhat G S and Co-authors 2001 BOBMEX - the Bay of Bengal Monsoon Experiment; Bull. Amer. Meteor. Soc. 82 2217-2243.

Businger J A, Wyngaard J C and Izumi Y 1971 Flux profile relationships in the atmospheric surface layer; J. Atmos. Sci. 28 181-189.

Dyer A J 1974 A review of flux profile relationships; Boundary-Layer Meteorol. 7 363-372.

Garratt J R 1992 The atmospheric boundary layer; (New York: Cambridge Univ. Press), 316 pp.

Farouki O T 1986 Thermal properties of soil; Series on rock and soil mechanics, Vol. 11, Trans Tech Publishers, Clausthal-Zellerfeld, Germany.
Hicks B B 1976 Wind Profile Relationships from the Wangara Experiment; Quart. J. Roy. Meteor. Soc. 102 $535-551$.

Hollinger D Y, Goltz S M, Davidson E A, Lee J T, Tu K and Valentine H T 1999 Seasonal patterns and environmental control of carbon dioxide and water vapour exchange in an ecotonal boreal forest; Glob. Change. Biol. 5 891-902.

Hosom David S, Weller R A, Payne R E and Prada K E 1995 The IMET (Improved Meteorology) Ship and buoy systems; J. Atmos. Oceanic Technol. 12 527-540.

Kaimal J C and Finnigan J J 1994 Atmospheric boundary layer flows - their structure and measurement; (New York: Oxford University Press).

Mahrt L 2007 The influence of nonstationarity on the turbulent flux-gradient relationship for stable stratification; Boundary-Layer Meteorol. 125 245-264.

Mahrt L 2008 Bulk formulation of surface fluxes extended to weak-wind stable conditions; Quart. J. Roy. Meteor. Soc. 134 1-10.

Monin A S 1970 The atmospheric boundary layer; Annu. Rev. Fluid Mech. 2 225-247.

Monin A S and Yaglom A M 1975 Statistical Hydrodynamics; MIT Press.

Nakamura R and Mahrt L 2005 A study of intermittent turbulence with CASES-99 tower measurements; BoundaryLayer Meteorol. 114 367-387.

Narasimha R, Sikka D R and Prabhu A 1997 The Monsoon Trough Boundary Layer (Bangalore, India: Indian Academy of Sciences), $422 \mathrm{pp}$.

Panofsky H A and Dutton J A 1984 Atmospheric Turbulence: Models and Methods for Engineering Applications. (New York: John Wiley \& Sons).

Rao Kusuma G and Narasimha R 2006 Heat flux scaling for weakly forced turbulent convection in the atmosphere; J. Fluid. Mech. 547 115-135.

Rao P S 2005 Arabian Sea Monsoon Experiment: An overview; Mausam 56 1-6.

Schmid H P, Grimmond C S B, Cropley F, Offerle B and $\mathrm{Su} \mathrm{H}$ B 2000 Measurements of $\mathrm{CO}_{2}$ and energy fluxes over a mixed hardwood forest in the mid-western United States; Agric. For. Meteorol. 103 357-374.

Stull R B 1988 Introduction to Boundary Layer Meteorology. (Dordrecht, Netherlands: Kluwer Academic Publishers).

Vernekar K G, Sinha S, Sadani L K, Sivaramakrishnan S, Parasnis S S, Brij Mohan, Dharmaraj S, Patil M N, Pillai J S, Murthy B S, Debaje S B and Bagavathsingh A 2003 An Overview of the Land Surface Processes Experiment (Laspex) over a Semi-Arid Region of India; Boundary-Layer Meteorol. 106 561-572.

Wilczak J M, Oncley S P and Stage S A 2001 Sonic anemometer tilt correction algorithms; Boundary-Layer Meteorol. 99 127-150.

Wilson K B and Baldocchi D D 2000 Seasonal and interannual variability of energy fluxes over a broadleaved temperate deciduous forest in North America; Agric. For. Meteorol. 100 1-18.

Wilson $\mathrm{K}$ and Co-authors 2002 Energy balance closure at FLUXNET sites; Agric. For. Meteorol. 113 223-243.

Zilitinkevich S S and Esau I N 2007 Similarity theory and calculation of turbulent fluxes at the surface for the stably stratified atmospheric boundary layer; BoundaryLayer Meteorol. 125 193-205. 